\title{
KONSEP ARSITEKTUR BERKELANJUTAN ARSITEKTUR VERNAKULAR RUMAH LAMIN SUKU DAYAK KENYAH
}

\author{
Mafazah Noviana \\ Staf Pengajar Jurusan Desain, PS. Arsitektur, Politeknik Negeri Samarinda \\ E-mail: Mafazah79@gmail.com
}

\begin{abstract}
Dayak Kenyah tribe is one of the most original Kalimantan spread all over the territory. Dayak Kenyah people call their house with Lamin or Amin. The concept of vernacular architecture is the development of folk architecture, characterize ecological architecture, architectonic and natural. This concept is in line with the concept of sustainable architecture. Similarly Lamin Dayak Kenyah, what is sustainable architecture concepts are applied in the building. One of the Dayak Kenyah settlement that is still awake in East Kalimantan is Pampang Village which is located in Kecamatan Samarinda Utara, Kelurahan Sungai Siring, Samarinda

The method used to find the concept of sustainable architecture Lamin Dayak Kenyah is qualitative research method with rationalistic paradigm. The data obtained by field observations in Dayak Kenyah village, the Village Pampang and from other sources such as the internet, books, magazins, and news paper.
\end{abstract}

Keywords: Lamin, vernacular concept, the concept of sustainable

\begin{abstract}
Abstrak
Suku dayak kenyah merupakan salah satu suku asli kalimantan yang paling banyak menyebar keseluruh pelosok wilayah. Orang Dayak Kenyah menyebut rumah tinggalnya dengan Lamin atau Amin. Konsep arsitektur vernakular merupakan pengembangan dari arsitektur rakyat, mencirikan arsitektur ekologis, arsitektonis dan alami. Konsep ini sejalan dengan konsep arsitektur berkelanjutan. Begitu pula dengan Lamin Suku Dayak Kenyah konsep-konsep arsitektur berkelanjutan apa sajakah yang diterapkan dalam bangunannya. Salah satu permukiman Suku Dayak Kenyah yang masih terjaga di Kalimantan Timur adalah Desa Pampang Samarinda yang terletak di Kecamatan Samarinda Utara, Kelurahan Sungai Siring.

Metode yang digunakan untuk melihat konsep arsitektur berkelanjutan pada rumah Lamin Suku Dayak Kenyah yaitu Metode penelitian kualitatif dengan paradigma rasionalistik. Data-data diperoleh dengan observasi lapangan di desa suku Dayak Kenyah, yaitu Desa Pampang dan dari sumber-sumber lain seperti internet dan media cetak.
\end{abstract}

Kata Kunci: Lamin, konsep vernakular, konsep berkelanjutan 
Mafazah Noviana, Konsep Arsitektur Berkelanjutan Arsitektur Vernakular Rumah Lamin Suku Dayak Kenyah

\section{PENDAHULUAN}

Arsitektur dibangun untuk mampu menjawab kebutuhan manusia dan mengangkat derajat hidupnya menjadi lebih baik, sehingga tidak bisa dilepaskan dari perkembangan kebudayaannya. Arsitektur itu sendiri adalah buah dari budaya yang dikembangkan secara terus menerus (Rapoport, 1969).

Kalimantan Timur memiliki banyak sekali jenis suku Dayak. Salah satu suku yang tertua dan terbesar adalah Suku Dayak Kenyah. Sampai saat ini Suku Dayak Kenyah merupakan suku yang mendominasi penduduk di Kalimantan secara keseluruhan. Dayak Kenyah berasal dari pedalaman bagian Utara Kalimantan Timur yaitu daerah Apo Kayan. Suku Dayak merupakan suku asli Kalimantan yang hidup berkelompok yang tinggal di pedalaman, di gunung dan di tepi sungai. Salah satu suku dayak yang tinggal menyebar di berbagai pelosok wilayah Kalimantan Timur adalah Suku Dayak Kenyah. Desa Pampang terletak di Kelurahan Sungai Siring, Kecamatan Samarinda Utara, merupakan perkampungan masyarakat Dayak Kenyah yang dijadikan sebagai kawasan wisata budaya di wilayah Kota Samarinda. Penduduknya berasal dari Apo Kayan Kabupaten Bulungan yang berpindah ke wilayah ini melalui Muara Wahau, Long Segar, Tabang, Long Iram Kabupaten Kutai.

Pada masa lalu, rumah adat memegang peranan penting dalam kehidupan masyarakat. Karena di sanalah biasanya dilaksanakan upacara-upacara adat yang memayungi kehidupan mereka bersama. Tidak terkecuali dengan rumah Lamin bagi suku Dayak. Lamin awalnya tumbuh dari lingkungan petani lokal yang cenderung berkelompok satu sama lain. Di sana mereka bisa hidup bersama sebagai suatu kesatuan yang membedakannya dengan kelompok lain. Tidak heran bila bagi orang Dayak lamin adalah simbol kebesaran.
Pada masa sekarang ini keberadaan rumah Lamin semakin sulit untuk ditemui, terutama rumah Lamin dengan fungsi aslinya. Kemajuan teknologi dan komunikasi membawa pengaruh pada modernisasi kehidupan masyarakat tradisional, termasuk juga kehidupan Suku Dayak Kenyah. Hal ini juga berpengaruh pada bentuk fisik rumah tradisional mereka. Konsep arsitektur vernakular merupakan pengembangan dari arsitektur rakyat, mencirikan arsitektur ekologis, arsitektonis dan alami. Untuk itu penulis ingin mengkaji lebih dalam mengenai konsep vernakular Lamin yang sejalan dengan konsep arsitektur berkelanjutan bila dikaitkan dengan iklim tropis daerah Kalimantan Timur yang cirinya adalah mendapat sinar matahari sepanjang tahun, curah hujan yang melimpah dan kadang disertai angin yang kencang.

Penelitian ini bertujuan untuk Mengetahui konsep arsitektur berkelanjutan diterapkan pada arsitektur vernakular rumah lamin Suku Dayak Kenyah dan mengetahui aspek-aspek arsitektur berkelanjutan apa saja yang ada pada arsitektur vernakular rumah lamin Suku Dayak Kenyah.

\section{KAJIAN PUSTAKA}

\section{Konsep Arsitektur Berkelanjutan}

Pengertian Arsitektur yang berkelanjutan adalah arsitektur yang memenuhi kebutuhan saat ini, tanpa membahayakan kemampuan generasi mendatang, dalam memenuhi kebutuhan mereka sendiri. Kebutuhan itu berbeda dari satu masyarakat ke masyarakat lain, dari satu kawasan ke kawasan lain dan paling baik bila ditentukan oleh masyarakat terkait (Steele, 1997).

Pengaruh bangunan pada lingkungan menurut Peter Graham (2003), harus memikirkan Life cycle dari bangunan yang 
mengefek pada bahan bangunan yang digunakan. Sementara siklus bahan atau rantai bahan yang utuh menurut Heizn Frick (1997), adalah melingkar tidak terputus, yang terputus berarti mengalami gangguan.

Ada 3 (tiga) tolok ukur sustainable development, yaitu:

1. Tolok ukur ekonomi (economic sustainability)

2. Tolok ukur lingkungan (environmental sustainability)

3. Tolok ikur sosial (social sustainability)

Dari ketiga tolok ukur di atas oleh Innovative Design (2005) dikembangkan menjadi 6 (enam) parameter sustainabilitas, yaitu:

1. Biaya operasi dan pemeliharaan bangunan yang rendah

2. Menjaga kelestarian lingkungan alam sekitar

3. Bangunan yang sehat, aman, dan nyaman

4. Mendukung nilai-nilai masyarakat setempat

5. Bangunan yang sesuai kebutuhan

6. Bangunan sebagai alat pembelajaran sustainabilitas

\section{Konsep Arsitektur Vernakular}

Arsitektur vernakular adalah arsitektur yang tumbuh dan berkembang dari arsitektur rakyat yang lahir dari masyarakat etnik dan berakar pada tradisi etnik, serta dibangun oleh tukang berdasarkan pengalaman (trial and error), menggunakan teknik dan material lokal serta merupakan jawaban atas setting lingkungan tempat bangunan tersebut berada dan selalu membuka untuk terjadinya transformasi. (Turan,1990). Turan mengklasifikasikan arsitektur vernakular dalam beberapa tinjauan, yaitu sebagai berikut:

1. Arsitektur vernakular sebagai produk.
2. Arsitektur vernakular sebagai proses.

3. Arsitektur vernakular dari tinjauan filosofis.

4. Arsitektur vernakular sebagai ilmu pengetahuan.

Rapoport (dalam Turan 1990), membagi arsitektur dilihat dalam dua bagian, yaitu vernakular sebagai sebuah proses dan vernakular sebagai sebuah produk. Dalam memandang arsitektur vernakular terkait pada proses pembuatannya. Rapoport menjelaskan bahwa pada prosesnya arsitektur vernakular tidak memiliki atau tidak punya identitas perancang (arsitek) secara jelas atau dengan kata lain arsitektur vernakular tidak dirancang oleh seorang arsitek, maksud dan tujuan merancang/membangun bukan dengan maksud menonjolkan diri, percaya dengan satu model bangunan tunggal dengan variasi bentuk yang terbatas, selain itu pada prosesnya arsitektur vernakular lebih alami respon terhadap lingkungan dan manusia sebagai pengguna, sifatnya alami, ukuran bangunan berbeda-beda tidak mengacu pada standar perancangan bangunan tapi sematamata sesuai dengan kebutuhan. Bentuk bangunan atau massa dalam proses perancangannya cenderung konkruen atau sebagun dengan ukuran spasial dibagi secara merata. Sementara itu pada proses perubahannya arsitektur vernakular mengalami perubahan yang sangat lambat dan bersifat sementara.

Rapoport menjelaskan beberapa point tentang karakter arsitektur vernakular sebagai produk yaitu arsitektur vernakular mempunyai tingkat atau derajat klasifikasi sesuai budaya dan tempat, model denah, bentuk dan transisi sangat spesifik, mempunyai hubungan antar elemen dan kaidah, penggunaan material serta kualitas bentuk tertentu. Efektif menjawab/respon terhadap lingkungan setempat, mempunyai kompleksitas dalam skala yang lebih besar 
Mafazah Noviana, Konsep Arsitektur Berkelanjutan Arsitektur Vernakular Rumah Lamin Suku Dayak Kenyah

dalam menetapkan sesuatu yang spesifik, serta variasi sepanjang waktu dalam arsitektur vernakular juga menerima dan terbuka terhadap suatu bentuk perubahan.

\section{Suku Dayak Kenyah}

Suku bangsa Kenyah merupakan salah satu suku bangsa yang tinggal di pedalaman Pulau Kalimantan. Suku bangsa ini sering digolongkan sebagai penduduk pedalaman dengan sebutan Dayak. Suku bangsa Kenyah disini berasal dari Kecamatan Long Nawang, Kabupaten Bulungan, Propinsi Kalimantan Timur yaitu sekitar Apo Kayan atau di bagian hulu Sungai Mahakam dan Sungai Kayan yang aliran sungainya melintasi wilayah kabupaten yang berbeda dan bermuara ke Laut Sulawesi (Sedyawati, 1995 : 18).

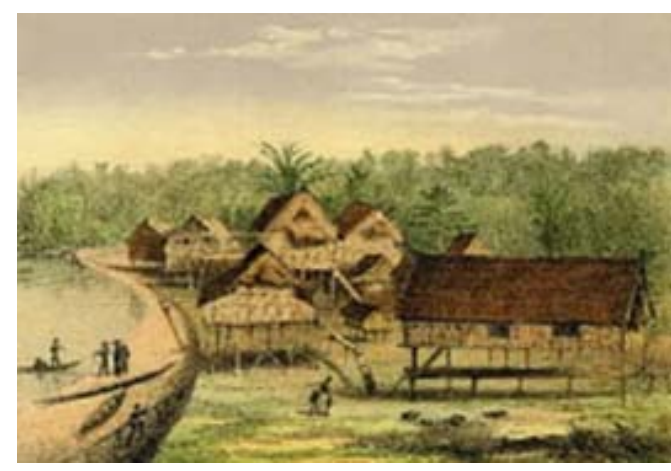

Gambar. 1

Pemukiman Suku Dayak di tepi Mahakam Lukisan: Carl Bock, 1879

Masyarakat Dayak semula tinggal di tepi pantai, tetapi kemudian terdesak semakin jauh ke pedalaman oleh pendatang Melayu. Mereka tinggal di tepi-tepi sungai yang berfungsi sebagai sarana komunikasi dan perjalanan.

\section{Proses Pembuatan Rumah Lamin}

Pembuatannya rumah lamin dilakukan secara bergotong royong. Sebagaimana umumnya masyarakat tradisional, proses pembuatannya juga tidak 40 sembarangan. Semuanya dilakukan dengan perhitungan matang dan sebuah prosesi. Umpamanya saja dalam hal pemilihan waktu pembangunannya, material bangunan, hingga "isyarat-isyarat" alam berikut pantangannya (seperti munculnya pelangi, ular yang melintas, burung yang berbunyi, dsb), agar mereka terhindar dari segala bencana. Setelah selesai, lamin bisa ditempati oleh puluhan atau beberapa kepala keluarga berikut dengan anggotanya. Di sanalah mereka hidup bersama, bersosialisasi sebagai keluarga besar yang saling tolong menolong di antara sesamanya. Karena banyak penghuni, bagi masyarakat Dayak lamin boleh dibilang adalah kampung itu sendiri atau setidaknya cikal bakal dari desa berikutnya.

\section{Rumah Lamin Suku Dayak Kenyah di Desa Pampang}

Desa Pampang terletak di Kelurahan Sungai Siring, Kecamatan Samarinda Utara (sekitar $25 \mathrm{~km}$ dari pusat kota Samarinda). Desa Pampang merupakan perkampungan masyarakat Dayak yang dijadikan sebagai kawasan wisata budaya di wilayah Kota Samarinda. Penduduknya termasuk suku Dayak Kenyah yang berasal dari Apokayan Kabupaten Bulungan yang berpindah ke wilayah ini melalui Muara Wahau, Long Segar, Tabang, Long Iram Kabupaten Kutai, yang dimulai dengan 35 kepala keluarga pada tahun 1967 dengan perpindahan dalam kelompok yang bergerak dari arah utara menuju selatan, hingga tahun 1973-an. Salah satu jurnal yang membahas tetang rumah lamin Suku Dayak Kenyah di Desa Pampang adalah jurnal berjudul "Mengenali Arsitektur Rakyat dari Perubahan Bentuk Lamin Masyarakat Dayak di Desa PampangSamarinda" yang ditulis oleh Siti Rachima, dkk. Jurnal tersebut membahas tentang beberapa perubahan rumah lamin di desa Pampang yang terjadi saat ini akibat perubahan kebutuhan dan budaya masyarakatnya, namun arsitektur lamin tetap dianggap sebagai arsitektur rakyat, karena 
dirancang oleh dan untuk kebutuhan masyarakat Desa Pampang.

\section{METODE PENELITIAN}

Penelitian ini merupakan penelitian kualitatif dengan paradigma rasionalistik. Data-data diperoleh dengan observasi lapangan di desa suku Dayak Kenyah, yaitu Desa Pampang dan dari sumber-sumber lain seperti internet dan media cetak. Desa Pampang terletak di Kecamatan Samarinda Utara, Kelurahan Sungai Siring.

Pembahasan dilakukan dengan riset kepustakaan, yaitu melalui literatur-literatur dan media informatif lain yang berhubungan dengan pembahasan.

\section{PEMBAHASAN}

\section{Rumah Lamin Suku Dayak Kenyah Sebagai Arsitektur Vernakular}

Bentuk arsitektur lamin suku Dayak Kenyah tidak seberapa jauh berbeda dengan rumah-rumah adat dari suku Dayak lainnya, seperti suku Dayak Tunjung, Benuaq Bahau dan lain-lain. Tetapi suatu ciri khas dari sebuah rumah adat suku Dayak Kenyah adalah meriahnya seni lukis dan seni ukir yang menghiasi rumah adat mereka dengan motif-motif ornamen yang khas dan dinamis.

Lamin didirikan menghadap ke arah sungai dengan bentuk dasarnya berupa empat persegi panjang, panjangnya dapat mencapai 200 meter sedangkan lebarnya 20 hingga 25 meter. Di halaman sekitar lamin terdapat patung-patung kayu berukuran besar yang merupakan persembahan nenek moyang yang disebut dengan Blang.

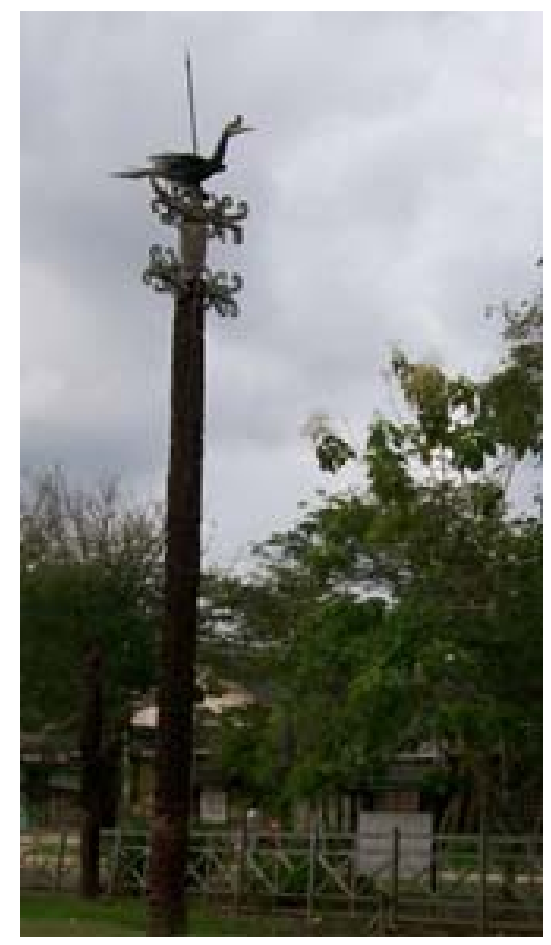

Gambar. 2

Patung kayu (blang) tempat persembahan nenek moyang (Koleksi Penulis)

Lamin dihuni oleh bayak keluarga yang mendiami bilik-bilik (kamar). Bagian depan lamin merupakan sebuah serampi panjang yang berfungsi sebagai tempat menyelenggarakan upacara perkawinan, melahirkan, kematian, pesta panen dan lain sebagainya. Di bagian belakang serambi terdapat deretan bilik-bilik besar, masingmasing dihuni oleh 5 kepala keluarga. Lamin kediaman bangsawan dan kepada adat biasanya penuh dengan hiasan atau ukiranukiran yang indah mulai dari tiang, dinding hingga puncak atap dan ornamen pada puncak atapnya mencuat hingga 3 atau 4 meter. Dinding lamin milik bangsawan atau kepala adat terbuat dari papan, sedangkan Lamin masyarakat biasa hanya terbuat dari kulit kayu.

Secara umum komponen Lamin Suku Dayak Kenyah akan dibagi menjadi 3 bagian, yaitu sebagai berikut: 
Mafazah Noviana, Konsep Arsitektur Berkelanjutan Arsitektur Vernakular Rumah Lamin Suku Dayak Kenyah

1. Bagian Atap

Kepang (atap) Lamin berbentuk pelana dengan kemiringan yang cukup ekstrim. Atap dibuat dari sirap berbahan kayu ulin (kayu besi). Sirap terbuat dari jejeran kepingan kayu ulin berukuran 70 x 40 $\mathrm{cm}$. Setiap lembaran kayu tersebut diberi lubang sebagai tempat pengikat, kemudian disusun secara teratur sehingga bagian tepi lembar yang satu menutupi tepi lembang yang lainnya. Bagian puncak atap ditutup dengan kulit keras yang diikat sedemikian rupa sehingga cukup untuk menahan terpaan angin. Pada bagian ujung-ujung atap dipasang hiasan berupa kayu les yang sudah diukir.

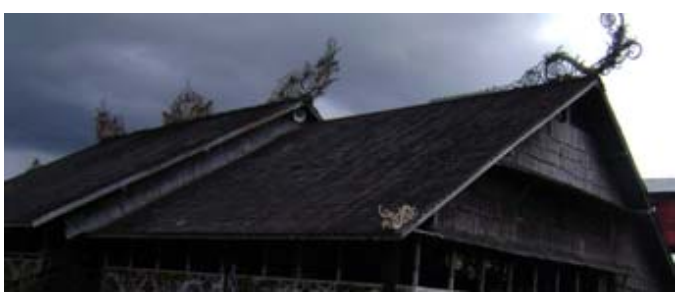

Gambar. 3 Atap Rumah Lamin (Koleksi Penulis)

\section{Bagian Dinding}

Dinding lamin terbuat dari jejeran papan berbahan kayu meranti. Dinding inilah yang akan membentuk peruntukan ruang pada lamin. Dinding bagian luar dilapisi dengan ornamen-ornamen khas suku Dayak Kenyah. Sedangkan tiang atas dibuat dari batang pohon belengkanai berdiameter $0,5 \mathrm{~m}$. Fungsi utama tiang-tiang atas adalah untuk menyangga atap pada bagian serambi (Usoq).

Isi dari Lamin adalah orang yang memiliki hubungan kekeluargaan seketurunan. Kamar-kamarnya bisa berjumlah sampai 50 kamar dan panjangnya kurang lebih 300 meter.
Terdapat banyak bukaan di dindingnya yang berbentuk jendela, sehingga rumah sejuk, bias melihat pemandangan luar, sirkulasi udara lancar. Lalu di bawah kolomnya tidak tertutup dinding sehingga sirkulasi udara juga berjalan baik.

Lantai Lamin (Asoq) terdiri dari tiga bagian yaitu: Usoq (serambi), Bilik (kamar tidur) dan Jayung (dapur). Asoq tersusun dari 4 lapisan, yaitu merurat (gelagar pertama), mantuukng (gelagar kedua), lala (lantai bagian bawah) dan di atas lala dipasang lantai yang sebenarnya. Asoq terbuat dari jejeran kayu meranti yang dibuat papan dengan ukuran 1 x $10 \mathrm{~m}$.

\section{Bagian Kaki}

Lamin panjang dibangun di atas tiang yang tinggi yang disebut Sukaq. Sukaq berfungsi sebagai pondasi bangunan yang terbuat dari kayu ulin (kayu besi) berdiameter $1 / 2-1 \mathrm{~m}$ dan panjang $6 \mathrm{~m}$, dipancang ditanah dengan kedalaman $2 \mathrm{~m}$ dan berjarak $4 \mathrm{~m}$ antar tiang satu dengan tiang yang lain.

Untuk naik ke atas bangunan digunakan tangga yang terbuat dari batang kayu yang ditakik-takik membentuk undakan dan dapat ditarik ke atas dan disimpan di pelataran lamin, yang disebut dengan 'tangga behek'. Semua ini adalah sebagai upaya untuk mengantisipasi ancaman serangan musuh ataupun binatang buas. 


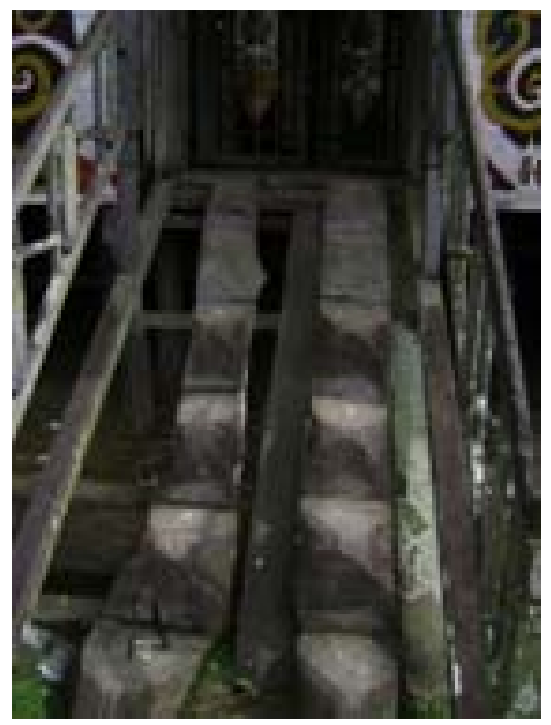

Gambar. 4 Tangga Behek (Koleksi Penulis)

\section{Konsep Arsitektur Berkelanjutan Pada Rumah Lamin Suku Dayak Kenyah}

Konsep arsitektur berkelanjutan yang terdapat pada Lamin Suku Dayak Kenyah akan diuraikan berikut ini berdasarkan paramater sustainabilitas.

1. Biaya operasi dan pemeliharaan bangunan yang rendah:

Sebagian besar bangunan rumah lamin ini menggunakan kayu yang mudah di dapat di hutan Kalimantan Timur, yaitu kayu besi (ulin), kayu meranti dan kayu kapur. Bahan bangunan lamin biasanya dipilih dari bahan-bahan terbaik dan mudah dijadikan rumah yang diambil dari hutan. Untuk tiang, mereka biasanya menggunakan kayu ulin atau meranti, yang terkenal karena kekuatannya. Sementara untuk lantai, mereka menggunakan bahan kayu, rotan atau bambu. Sedangkan untuk dinding, mereka menggunakan kulit kayu yang telah dikeringkan.

Kayu Ulin atau disebut juga dengan kayu besi adalah pohon berkayu merupakan salah satu jenis kayu hutan tropika basah yang tumbuh secara alami di wilayah Kalimantan. Kayu ulin tahan terhadap perubahan suhu, kelembaban dan pengaruh air sehingga sifat kayunya sangat keras. Kayu Meranti merupakan salah satu jenis kayu khas daerah tropis yang juga memiliki kekuatan, keawetan dan tahan terhadap serangan rayap dan serangga penggerek.

Berdasarkan beberapa penelitian atap sirap yang terbuat dari ulin mampu bertahan antara 30 sampai 60 tahun, akan lebih tahan lagi apabila bangunan menggunakan sangkuak (bilah atap dari papan ulin dengan panjang sekitar $70 \mathrm{~cm}$ dan lebar $20 \mathrm{~cm}$ dengan tebal hampir satu sentimeter). Dengan menggunakan material yang memiliki daya tahan tinggi berarti bahwa bangunan tidak mudah rusak sehingga biaya pemeliharaannya menjadi rendah, karena tidak perlu sering menggantinya. Selain itu penggunaan material lokal menjadi mudah mendapatkan dan murah bila harus mengganti.

2. Menjaga kelestarian lingkungan alam sekitar

Material bangunan yang diambil dari lingkungan adalah yang terpilih dan tidak akan habis. Kayu ulin (kayu besi) dan kayu meranti sebagai bahan utama rumah lamin merupakan kayu yang terkenal karena kekuatannya, sehingga masa pakainya menjadi lama. Masyarakat Suku Dayak Kenyah menggunakan kayu secukupnya saja, elemen-elemen bangunan tidak akan diganti jika belum rusak.

3. Bangunan yang sehat, aman, dan nyaman

Lamin memiliki sirkulasi udara yang cukup. Bentuknya rumah panggung (memiliki kolong), dengan ketinggian bisa melebihi ketinggian 3 meter merupakan tempat sirkulasi udara ke dalam ruangan, sehingga meskipun bentuknya rumah panjang tetapi hawa di dalam ruangan tidak terasa panas. Selain itu pada bagian 
Mafazah Noviana, Konsep Arsitektur Berkelanjutan Arsitektur Vernakular Rumah Lamin Suku Dayak Kenyah

belakang rumah terdapat banyak jendela untuk menjaga agar udara dapat ke luar masuk ruangan dengan mudah.

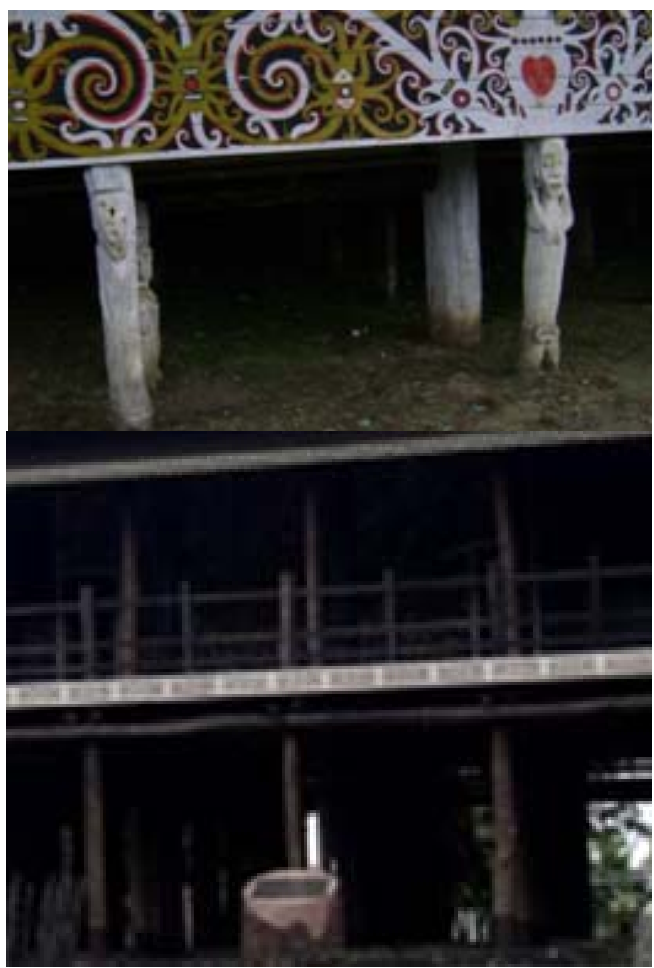

Gambar. 5 Kolong pada Lamin (Koleksi Penulis)

Alasan lamin dibuat tinggi dari permukaan tanah juga sebagai sarana defensif terhadap ancaman atau gangguan yang datang dari luar. Misalnya gangguan dari binatang buas atau musuh yang datang menyerang. Sebagaimana diketahui, suku Dayak meski pada awalnya berasal dari satu keturunan namun pada perkembangannya terbagibagi lagi dalam banyak sub suku, yang beberapa di antaranya bisa saja berperang satu sama lain. Dengan adanya lamin, maka mereka dapat melindungi anggota keluarganya dari ancaman musuh.

Bahan Atap sirap Lamin membuat bagian dalam ruangan menjadi terasa sejuk, karena udara luar dapat dengan mudah keluar masuk melalui pori-pori kayu. Bentuk atap pelana dengan kemiringan ekstrim dan cukup lebar merupakan tanggapan terhadap curah hujan yang tinggi di wilayah Kalimantan Timur agar air hujan dapat langsung tidak terbuang dan diserap oleh tanah.

4. Mendukung nilai-nilai masyarakat setempat

Masyarakat Suku Dayak Kenyah sangat menjunjung tinggi nilai spiritual yang membentuk suatu ikatan kultural yang kuat antara manusia dan alam. Kepercayaan pada alam gaib sangat mempengaruhi proses pembangunan rumah adat. Sebelum pembuatan lamin dimulai, terlebih dahulu kepala kampung, kepala adat dan para orang tua memilih dua orang warga untuk mencari lasan palaki (lahan tempat didirikannya lamin), yaitu sebidang tanah yang subur, kering dan biasanya menghadap ke sungai. Untuk menentukan lahan yang tepat, dua orang yang telah ditugaskan tersebut menunggu pertanda dari roh nenek moyang melalui perantara burung elang. Sebelum memulai pembangunan lamin, terlebih dahulu diadakan upacara adat dengan menggunakan sesajen.

Pada Suku Kenyah rumah panjang merupakan kelompok kekerabatan dan unit upacara keagamaan yang umum, misalnya upacara mamat diadakan dari, untuk dan oleh komunitas rumah panjang (lamin). menggambarkan sebuah rumah panjang suku dayak yang berhiaskan sejumlah tengkorak kepala di berandanya, setiap bagian di rumah panjang (lamin) suku Dayak memiliki arti penting dalam hubungannya dengan sistem-sistem kepercayaan, sebelum mereka menanjaki pintu masuk mereka harus mengikuti sejumlah kebiasaan tertentu dan mempercayai banyak ramalan dan petanda. 
Vol. 1, No. 1, Oktober 2013

Dengan demikian, lamin boleh dibilang adalah pusat kebudayaan masyarakat Dayak. Selain sebagai tempat tinggal, kesatuan identitas, di lamin juga mereka dapat menyelenggarakan adat istiadat atau tradisi mereka seperti bentian (pengobatan tradisional bagi anggota keluarga yang sakit), kuangkai (upacara pemakaman tulang belulang leluhur).

\section{Bangunan yang sesuai kebutuhan}

Lamin pada umumnya merupakan communal long houses yang dihuni oleh beberapa keluarga mencermikan budaya masyarakat yang menganut sistem Multifamily yaitu suatu kelompok keluarga yang tinggal bersama. Ukuran sebuah Lamin bervariasi menyesuaikan kebutuhan. Panjangnya berkisar antara 100 - 200 m dan lebarnya antara 20 - 25 meter dan dihuni 60 keluarga. Kamarkamar tidur berukuran kurang lebih $8 \mathrm{x}$ 15 meter dan di dalamnya tinggal lebih dari lima kepala keluarga. Hal ini sangat menghemat tempat, dibanding jika masing-masing keluarga memiliki rumah sendiri maka akan jauh lebih banyak lahan yang terpakai.

Menurut Siti Rachima, dkk (2004), bentuk lamin pada permukiman masyarakat Dayak Di desa Pampang berbeda dengan Lamin pada umumnya, akibat telah terjadinya perubahan kebutuhan dan budaya masyarakat setempat. Dari semula tinggal secara komunal dalam satu rumah yang besar dan panjang, kini berubah menjadi warga satu kampung dengan unit hunian sendirisendiri per keluarga. Namun demikian, orientasi pada arah alur sungai tetap dipakai, dan terwujud dalam bentuk jalan desa yang dibangun dengan mengikuti alur sungai. Pembagian ruang Lamin tunggal di desa Pampang hampir sama dengan Lamin pada umumnya, hanya ukurannya yang relatif kecil, dengan ketinggian hanya sekitar $1-1,5$ meter dari tanah. Namun demikian, rumah lamin di Desa Pampang masih menyisakan jejak ruang komunal berupa adanya ruang dalam yang lapang dan dapat menampung beberapa puluh orang di dalamnya untuk kegiatan-kegiatan yang bersifat perkumpulan. Satu-satunya longhouse di Desa Pampang terletak di tengah desa berfungsi sebagai balai adat atau balai desa untuk menampung kegiatan bersama masyarakat desa.

Suku Dayak Kenyah menggunakan seluruh bagian bangunan Lamin untuk melangsungkan kehidupannya sehari-hari. Usoq yang panjang dapat menampung ratusan tamu, di tempat inilah diadakan upacara atau ritual adat yang diselenggarakan secara gotong-royong. Halaman Lamin yang luas menjadi tempat bermain anak setiap hari dan juga tempat diadakannya ritual adat jika Usoq sudah tidak mampu menampung upacara tersebut. Pojok-pojok halaman menjadi tempat peletakkan patung-patung persembahan nenek moyang. Halaman bagian samping sampai belakang Lamin berfungsi sebagai kebun dengan ditumbuhi bermacam-macam pohon sayur-sayuran dan buah-buahan. Bagian kolong rumah dimanfaatkan untuk memelihara binatang ternak seperti ayam dan babi.

Seluruh bagian Lamin mempunyai fungsi penting bagi penghuninya, tidak ada bagian rumah yang dibangun dengan sia-sia, mulai dari halaman di sekitarnya maupun bangunannya semua dibuat untuk beraktivitas dan memenuhi kebutuhan hidup sehari-hari. 
Mafazah Noviana, Konsep Arsitektur Berkelanjutan Arsitektur Vernakular Rumah Lamin Suku Dayak Kenyah

\section{KESIMPULAN DAN SARAN}

Prinsip-prinsip arsitektur berkelanjutan yang ada pada Bangunan Lamin Suku Dayak Kenyah adalah sebagai berikut:

1. Biaya operasi dan pemeliharaan bangunan yang rendah

Bahan bangunan lamin dipilih dari bahanbahan terbaik dan mudah dijadikan rumah yang diambil dari hutan, agar bangunan tersebut bisa bertahan lama.

2. Menjaga kelestarian lingkungan alam sekitar

Mereka menggunakan kayu secukupnya saja, elemen-elemen bangunan tidak akan diganti jika belum rusak.

3. Bangunan yang sehat, aman, dan nyaman Bentuk rumah panggung sebagai sirkulasi udara sekaligus sebagai sarana defensif terhadap ancaman atau gangguan yang datang dari luar.

4. Mendukung nilai-nilai masyarakat setempat

Lamin adalah pusat kebudayaan masyarakat Dayak. Selain sebagai tempat tinggal, kesatuan identitas, di lamin juga mereka dapat menyelenggarakan adat istiadat atau tradisi.

5. Bangunan yang sesuai kebutuhan Rumah Lamin tunggal di Desa Pampang dibangun sesuai dengan kebutuhan masyarakat yang telah mengalami perubahan. Sedangkan longhouse berfungsi sebagai balai adat atau balai desa untuk menampung kegiatan bersama masyarakat desa.

Saran untuk pemerintah yaitu dapat mengaplikasikan model rumah lamin untuk perumahan dan permukiman di wilayah Kota Samarinda, terutama untuk daerah-daerah rendah yang rawan banjir. Sedangkan untuk arsitek diharapkan dapat merancang rumah-rumah diperkotaan dengan menerapkan Konsep Arsitektur berkelanjutan rumah lamin tentunya dengan melakukan berbagai penyesuaian terhadap kondisi masyarakat dan lingkungan.

\section{DAFTAR PUSTAKA}

Frick, Heizn. 1997. Ilmu Bahan Bangunan. Kanisius. Semarang.

Graham, Peter. 2003. Building Ecology - First Principle for a Suistainable Built Environment, Blackwell Science Ltd.

James, Steele. 1997. Sustainable Architecture. Mc Graw Hill. New York.

Rachima, Siti, dkk. 2004. Mengenali Arsitektur Rakyat dari Perubahan Bentuk Lamin Masyarakat Dayak di Desa Pampang Samarinda. Universitas Pancasila. Jakarta

Rapoport, A. 1969. House, Form and Culture. Prentice Hall. New York.

Sedyawati, Edi, dkk., 1995. Konsep Tata Ruang Suku Bangsa Dayak Kenyah di Kalimantan Timur. Departemen Pendidikan dan Kebudayaan. Jakarta.

Turan, Mete. 1990. Vernacular Architecture. Grower Publishing, Company Old, Vermon. USA. 